\title{
Kentin Hücresel Boyutu: Bağcılar (İstanbul) Üzerine Bir Deneme
}

\section{The Cellular Dimension of the City: An Essay on Bağcllar (İstanbul)}

\author{
Gülcan SARP ${ }^{1}$ (D), Kadir TEMURÇİN ${ }^{1}$ (D), Yolcu ALDIRMAZ ${ }^{1}$ \\ ${ }^{1}$ Süleyman Demirel Üniversitesi, Fen Edebiyat Fakültesi, Coğrafya Bölümü, Isparta, Türkiye
}

ORCID: G.S. 0000-0002-5021-4918; K.T. 0000-0002-8726-3756; Y.A. 0000-0001-8669-192X

\section{öz}

Şehirsel alanlara dair bilgilerimiz yeni veri kaynaklarına bağlı olarak sürekli yenilenip, çeşitleniyor. Bu değişimde özellikle mekânsal veriler başat rol oynuyor. Artık şehri oluşturan unsurlar yüksek çözünürlükte ve doğrulukta analiz edilebiliyor. Böyle bir ilerleme de kentsel mekânın özgül yapısının daha rahat gözlemlenmesine rehberlik ediyor. Bu çalışma da İstanbul kentsel bölgesinin en problemli şehirsel alanlarından olan Bağcılar'ın mekânsal inşasına ve mevcut durumuna odaklanıyor. Bunu da yüksek çözünürlüklü uzaktan algılama verileri ve firmalara ait konumsal bilgileri kullanarak yapıyor. Çalışmanın bulguları ise şehrin dokusundaki dört farklı sürece dayanıyor. İlki saçaklanmayla başlayan şehirleşme sürecinin adeta "azman sanayi kentine" (Güvenç, 1993) bürünen gelişim şeklini yorumluyor. İkincisi zaman içerisinde konut sunum biçimlerindeki değişimi ve bunların uyumsuzluklarını içeriyor. Üçüncüsü yakın zamanda kentin muhtelif bölgelerinde ama özellikle büyük sanayi kuruluşlarının bulunduğu sahalardaki dönüşümleri ve sonuçlarını ele alıyor. Sonuncusu ise kentte kapanan ve faaliyetini sürdüren firmaların dağılış kalıbını sorguluyor. Söz konusu dört olgu, Bağcılar'ın mevcut sorunlarının önemli bir kısmının mekânsal düzensizliklerden kaynaklandığını gösteriyor.

Anahtar kelimeler: Kentsel Doku, Mekânsal Veri, Bağcılar

\section{ABSTRACT}

Our knowledge of urban areas is constantly being renewed and diversified depending on new data sources. Spatial data plays a particularly major role in this change. Currently the elements of a given city can be analyzed in high resolution and with great accuracy. Such progress guides the observation of the specific structure of urban spaces more easily. This study focuses on the spatial construction and current situation of Bağcılar, one of the most problematic urban areas of the city of Istanbul. This research has been conducted using high-resolution remote sensing data and positional information from companies. The findings of the study are based on four different processes in the city. The first interprets the development form of the urbanization process which starts with urban sprawl and develops into a "monstrous industrial city" (Güvenç, 1993). The second includes changes in housing presentation patterns over time and their mismatches. The third process focuses on the recent transformation and its consequences in various parts of the city, but especially in areas where large industrial enterprises are located. The final one questions the distribution pattern of the companies that have shut down and those that are operating in the city. All four cases show that a significant part of Bağcılar's current problems stem from spatial irregularities.

Keywords: Urban Texture, Spatial Data, Bağcılar

Başvuru/Submitted: 04.09.2019 • Revizyon Talebi/Revision Requested: 02.12.2019 • Son Revizyon/Last Revision Received: 04.12 .2019 • Kabul/Accepted: 10.12.2019 • Online Yayın/Published Online: 17.12.2019 


\section{EXTENDED ABSTRACT}

There is a common rhetoric among those who have been living in Istanbul for a relatively long time: these areas used to be fields or swamps. This sentence is of key importance in making sense of the urban development of Istanbul. Indeed, the inclusion of a new district or municipality in the urban area in Istanbul can happen in only a short period of time in a human lifetime. For these areas, the beginning of the story often happens in a similar way and for similar reasons. Intense migration, industrialization and informal settlement are the most frequent reasons. However, as the narrative progresses, different processes and conclusions for each place are listed one after the other. This is reflected above all in the spatial fabric of the related sites. Therefore, the analysis of the fabric of the city is very important for interpreting both the development of these areas and their current problems. With this approach this study focuses on Bağcılar, a settlement area with one of the most problematic spatial structures in the urban area of Istanbul.

In this context, two different data sources have been used in the study. The first source is comprised of images with sub-meter resolution obtained by remote sensing techniques. They provide an adequate framework for an object-oriented interpretation of the city's texture and evolution. The second data type is comprised of positional information of recently closed and currently existing enterprises. The enterprises have been spatially coded and the representative texture of both closed and existing enterprises have been analyzed. Thus, the association between the perceived shape of the city from a given height and the utilization under that structure has been established.

The findings of the study can be collected under four different categories. The first is that the oil stain growth, which has been the basic course of development in Istanbul until this period, has been relatively ineffective in Bağcılar. The development of the Bağcılar urban area initially started in the form of sprawling. Every area in the district was covered with buildings within a short time, so much so that in many places the land cover is comprised only of buildings and roads. Therefore, the phenomenon of sprawling is limited to a short-term effect. The second category includes change in the forms of housing presentation and their asymmetrical appearance. Gecekondu, which were widespread in the urban area of Istanbul until the 1980s, have been partially interrupted in Bağcılar and replaced by apartment buildings. At the beginning of the 2000s, luxury housing presentation forms became widespread in the district. Some stand side by side and are often in zoned areas for various sectors, while others are found irregularly dispersed among industrial plants. When they all converge, spatial conflicts increase. The third is the transformation observed in various parts of the city in recent years, especially in large industrial buildings. These structures are being replaced with Istanbul's favorite projects. However, this change does not mean that the industrial sectors of both Istanbul and Bağc1lar are on the decline. While large enterprises are dispersed in various parts of Istanbul, small facilities still dominate the spatial outlook of Bağcılar. The last textural feature is based on the distribution pattern of enterprises. The positional information indicates that enterprises have chosen a location in the city according to their wishes, except for a few restricted zones. This means that even discordant sectors are located side by side and on top of each other. The fact that the enterprises which are closing down have the same distribution pattern as the existing ones is a reflection of the recurrence of the problems. In short, the irregular structure formed by the buildings deforms their utilization.

In conclusion, the premature evolution of Bağcılar has caused a problematic structure in its existing texture. Although today there are some attempts to regulate the texture of the city, it is not easy to realize this in one of the busiest settlements of Istanbul. Even the ratio of the site that is planned to be restructured is as high as $70 \%$. In short, Bağcilar faces a pathological problem. This problem has resulted in the residents of the district leaving the area. Indeed, the population of the district has started to decrease for the first time in the last few years. 


\section{GÍRIŞ}

Coğrafyacılar, ilk kez gördükleri veya incelemeye karar verdikleri kenti, yüksek bir yerden izlemeyi ve kuşbakışı elde ettikleri panoramik görüntüler üzerinden çıkarımlar yapmayı severler (Swyngedouw, 2004). Onlar için böyle bir yaklaşımla kent, bakanın gördüğü şeye göre okunabilir bir metne dönüşür (de Certeau, 1988; Harvey, 2015). Başlangıçta bu, peripatetik bir eylem olarak düşünülebilir. Nispeten de öyledir. Ama dahası da vardır. Artık görüş açısı daha geniştir. Farklılıklar ortadadır ve çeşitli sınırlar çizilebilir. Gerçekten de kent araştırmacıları için önemlidir, sınırlar. İlgili yazın uyumsuzlukların orada yoğunlaştığına ve kenti anlamlandırmanın oradan başladığına işaret eder (Smith, 2015). Kimilerine göre kentsel peyzaj1 oluşturan bu mekânsal düzen; çelişkili, uyumsuz, heterojen ve hatta heteroklittir (Lefebre, 2011). Çünkü Chicago Sosyoloji Okulu temsilcilerinin vurguladığ 1 gibi kent, insan doğasındaki iyiyi ve kötüyü aşırılıklarıyla gösteren yerdir (Park, 2016). Nitekim kentler, yerleşim sistemleri içerisinde, farkl1l1kların bir arada bulunduğu ve yüksek derecede yoğunlaştığı alanlar olarak konumlandırılır (Davis, 1990; Davis, 2016; Sassen, 2000; Scott, 2017; Massey vd., 1999; Storper, 2013; Storper, 2015; Harvey, 1996; Schmid, 2014; Fujita, 1989; Glaeser, 2011).

Kentin kendisi gibi bu çeşitlilik de durağan değildir. Sürekli evrilme ve lokalleşme eğilimindedir. Bir anlamda kent ve onun tarihselliğini yansıtan kentleşme süreci, devamlı polarize olmuş ve yerelleşerek mozaiklenmiş yapılar üretmektedir (Roweis \& Scott, 1978; Scott, 1980; Scott \& Storper, 2014). Çoğunlukla insan ve firmaların; tavır, davranış ve kararlarına göre şekillenen söz konusu yapı, kent içi mekânın dokusunu oluşturmaktadır (Scott \& Storper, 2014). İşleyiş de tek yönlü değildir. Belirleyenle belirlenen arasındaki ilişki, diyalektik bir kalıpta ilerlemektedir (Soja, 1980). Kentsel mekânı üreten ve dönüştüren faktörler, benzer şekilde onlar tarafından şekillenir (Harvey, 2009; Harvey, 2016; Castells, 1983; Knox \& Pinch, 2010). Bu nedenle kentin dokusunu ve onun evrimini sunmak, aslında kenti anlamlandırma adına iyi bir başlangıçtır (Merrifield, 2017). Fakat sahip olduğu belirlenmişliklere rağmen hem kentin kendisi hem de onun dokusu görünenin aksine karmaşık bir şeydir (Harvey, 2016).

İfade edilen zorluk temelde iki referans noktasina dayanmaktadır. İlki kentsel mekânın benzersiz ve dolayısıyla da heterojen yapılar bütününden oluşmasıdır. Her bir unsur; konum veya boyut açısından özgün bir yapıya sahiptir (Goodchild, 1992). Bütünlükten yoksundur. Basitleştirmelere karş1 bozulmaya uğrar. Hatta genelleştirme çabaları bile tartışma meselesidir (Sun vd., 2006). Dolayısıyla kentin yapısal farklılıklarıyla analiz edilmesi birçok açıdan faydalı gibi görünmektedir. Mekâna ya da konuma ait bilgilerin bu şekilde doğrudan gösterimi, belki de Gould'un ifadesiyle verilerin kendilerini özgürce ifade etmelerine de imkân tanıacaktır (Gould, 1981). İkinci zorluk ise kentsel dokunun evrimi ile ilgilidir. Burada tıpk1 yerlerin biricikliği gibi (Massey, 2002), kentlerin de özgül doğasının olduğu görüşü hakimdir. Nitekim dünya genelinde kentsel mekânın evrimi, bazı karakteristikleriyle ve ifade edilen süreçlere verilen bazı isimlendirmeyle (banliyöleşme, soylulaşma ve sosyo-mekânsal ayrışma) benzer bir yörüngeyi izlemiş olsa da (Pacione, 2009) her şehirsel alan ayrı bir tarihselliğe (sürece) sahiptir (Arl1, 2010). Böylece herhangi bir kentte, sosyo-mekânsal dinamikleri biçimlendiren kuvvetlerin eşsizliği (tarihsel, kültürel, kurumsal vb.), mekânsal dokunun da eşsizliğini sağlamaktadır. Diğer bir ifadeyle ve özellikle de son yarım yüzyıldır belirginleşen çerçevesiyle, şehirsel mekânın görünümü hemen her yerde "bağlamsal olarak gömülü bir karaktere” sahiptir (Theodore vd., 2011).

$\mathrm{Bu}$ çalışma da böyle bir yaklaşımla şehirsel mekânın gelişimini, dokusal özellikleri üzerinden yorumlamayı amaçlamaktadır. Bunu da İstanbul kentsel bölgesi içerisinde yer alan, Bağcılar şehirsel alanı ile sınırlandırmaktadır. Ayrıca araştırmada hem doğrudan, yani uzaktan algilama teknolojileri kullanılarak ulaşılan bilgiler hem de firmaların lokasyon bilgileri üzerinden üretilen temsiller kullanılmaktadır. Böylece Bağcılar'ın gelişimi ve yapısı, yüksek çözünürlüğe ve doğruluğa sahip verilerle analiz edilmektedir.

\section{VERİ VE YÖNTEM}

Yakın zamanlı araştırmalar, diğer disiplinler gibi coğrafi yorumlamanın da veri kitlığından veri yoğun bir yapıya büründüğünü göstermektedir. Yaklaşık yarım yüzyılda algılayıcılardan ve konumsal ölçümlerden akan veriler, özellikle mekâna dair bilgilerin hızla artmasına neden olmuştur (Miller \& Goodchild, 2015). Bu değişim sadece niceliksel bir farklılaşmayı ifade etmemektedir. Aynı zamanda verilerin niteliğinde ve işlenmesinde de dikkate değer ilerlemeler meydana gelmiştir (He \& Weng, 2018). Söz konusu gelişmeler başta kent araştırmaları olmak üzere, birçok alanda radikal değişimlere yol açmıştır. Aynı zaman periyodunda hızla büyüyen ve birçok açıdan bir bütün halinde algılanamayacak olan mekânsal düzen, konumsal veriler ve obje tabanlı bilgiler sayesinde rahatlıkla işlenebilmektedir (Weng, 2014; Weng vd., 2018; Güvenç, 2018).

Bu araştırmada da, söz konusu verilerden her ikisi de (uzaktan algılama verileri ile mekânsal kodlamalar) kullanılacaktır. İlk 
Tablo 1: Kullanılan Görüntülerin Temel Özellikleri.

Table 1: Basic Characteristics of Images Used.

\begin{tabular}{ccccc}
\hline Üretim Tarihi & Verinin Cinsi & Konumsal Çözünürlük/ Ölçek & OrtoFoto Renk Durumu & Veri Formatı \\
\hline 1972 & Hava Fotoğrafı & $70 \mathrm{~cm}$ & Siyah Beyaz & GeoTIFF \\
1993 & Hava Fotoğrafı & $70 \mathrm{~cm}$ & Siyah Beyaz & GeoTIFF \\
2003 & Hava Fotoğrafı & $70 \mathrm{~cm}$ & Siyah Beyaz & GeoTIFF \\
2016 & Ortofoto & $30 \mathrm{~cm}$ & Renkli & GeoTIFF \\
\hline
\end{tabular}

veri kaynağı, yani uzaktan algılama tekniklerine dayalı bilgiler, kentin morfolojisine dair çıkarımlarda bulunmak için oldukça önemlidir. Ancak bu verinin obje tabanlı bilgileri elde edebilmek için yüksek çözünürlükte olması gerekmektedir. İlgili alan yazın ifade edilen yeterliliğin çalışılan bölgedeki kentlerin yapısı ile doğrudan ilişkili olduğunu göstermektedir. Bina yoğunluğunun, Avrupa ve Kuzey Amerika kentlerine göre daha fazla olduğu Asya kentlerinde çözünürlüğün daha fazla olması gerekmektedir (Welch, 1982). Çalışma alanı nispeten yoğun bir yerleşime sahip olsa da, kullanılan görüntülerin tamamı metre altı çözünürlüğe sahiptir. Dolayısıyla kentsel dokunun çıkarılmasında yeterlidir. Bu görüntüler Harita Genel Müdürlüğü'nden temin edilmiş ve bilgileri aşağıda sunulmuştur (Tablo 1). Araştırmada kullanılan ikinci veri kaynağ 1 ise, kentsel alandaki iktisadi işletmelerin konumlarını tespit etmek için yararlanılan Issyeri Takip Kayıtlarıdır. Bağcılar Belediyesi'nin düzenlediği veri, ilçe sınırları dâhilinde faaliyet gösteren veya yakın tarihte kapanan işletmelerin unvanı, türü, faaliyet alanı, durumu, adresi ve bazı kuruluşlar için koordinat bilgisini içermektedir.

Araştırmada kullanılan veriler, dört farklı aşamada işlenmiştir. İlk olarak, siyah beyaz hava fotoğraflarına Ortalama Kaydırma Segmentasyon işlemi uygulanmış ve fotoğraflar görsel olarak daha anlamlı ve analiz işlemleri için daha kolay yorumlanabilinir hale getirilmiştir. İkinci aşama da segmente edilmiş siyah beyaz görüntülerin sayısallaştırılması yapılmış ve her bir yapı objesi sayısal olarak elde edilmiştir. Üçüncü aşamada, renkli ortofoto görüntüsünde bulunan bina sinıfları manuel olarak sınıflandırılmıştır. Dördünü aşamada İşyeri Takip Kayıtlarındaki firmaların faaliyet alanları Nace Rev. 2 sinıflandırmasına göre düzenlenmiş ve ana faaliyet alanlarına göre birleştirilmiştir. Son aşamada ise İşyeri Takip Kayıtlarındaki bilgilerin mekânsal kodlaması yapılmıştır. Söz konusu işlemde öncelikle koordinatı verili olan işletmelerin adresleri tespit edilmiştir. Koordinatı verilmeyen işletmelerin ise, adres bilgisi kullanılarak yine belediyeden temin edilen hâlihazır haritadaki mahalle, caddesokak ve kapı numaraları gibi bilgilerinden yararlanılarak kodlaması yapılmıştır. Bu işlem, hem kapanan hem de mevcut işletmeler için uygulanmıştır. Böylece 10.993 kapanmış ve 15.300 adet halen faaliyette olan işletmenin koordinatı sayısallaştırılmıştır. Kapanmış firmalar 2015 sonrasındaki kapanan işletmelerin, faal firmalar ise ilçedeki mevcut tesislerin büyük bir bölümünü temsil etmektedir.

\section{BULGULAR}

Bağcılar'ın şehirleşme hikâyesi aslında biraz tanıdık... Benzer öyküler İstanbul kentsel bölgesinde yer alan ve özellikle 1950'lerden 2000'li yılların başına kadar şehirsel alana katılan birçok yerleşme için yazıldı (Örn. Maktav vd., 2000; Ayhan, 2019; Avcu \& Buldur, 2018). Hatta biraz daha uzaklarda, ama yine İstanbul'un kentleşme sürecinin bir parçası olarak biçimlenen sahalarda da yakın temalı anlatılara rastlamak mümkün (Örn. Kolukırık, 2012; Akova, 2012)... Yeni ulaşım akslarının gelişimi ile sanayinin hızlanan ademi merkezileşmesi, kırsaldan sürekli gelen ve genellikle kenti kendi kurallarına göre şekillendirme gayesindeki göçmen kitlesi, mülkiyetin belirsizliğinin ve özellikle de sermaye yetersizliğinin beslediği enformel yapılaşma ve tüm bunların sonucunda ortaya çıkan kontrolsüz bir kentsel büyüme olgusu söz konusu zaman diliminde İstanbul kentsel bölgesi için sıklıkla tekrarlanan fikirlerdir (Tekeli, 2013; Kuban, 1998; Tümertekin, 1997a; Tümertekin, 1997b). Fakat aynı dönemdeki yazınsal birikim bir bütün halinde incelendiğinde, kentin dokusunu şekillendiren güçlerde bir takım kırılımların ve dolayısıyla da mekânın inşasında bazı değişimlerin varlığı da kolaylıkla dikkati çekecektir. Bunlar iki kategoride toplanabilir. İlki tarihseldir ve sonuçları kentin peyzajında belirgin farklılaşmalara yol açmıştır. Örneğin tek katlı gecekondulaşmadan apartman tipi yapılara geçiş veya hazine arazisinin işgalinden kısmen parselli ve planlanmış konutların inşasının başlamasına ya da tek tek ve düzensiz görünüme sahip gecekondu tarzı binaların yerine/ yanına lüks konut projelerinin yapımının yaygınlaşması gibi olgular kentin mekânsal formunda asimetrik bir birlikteliği beraberinde getirmiştir ${ }^{1}$. İkinci ayrıntı ise, ilki ile kısmen bağlantılı olarak, bazı lokalitelerin kent genelindeki gelişim

1 Bu konuda başlıca çalışmalar için bakınız: (Tekeli, 2019; Tekeli, 2013; Tekeli, 2009; Güvenç, 2009) 

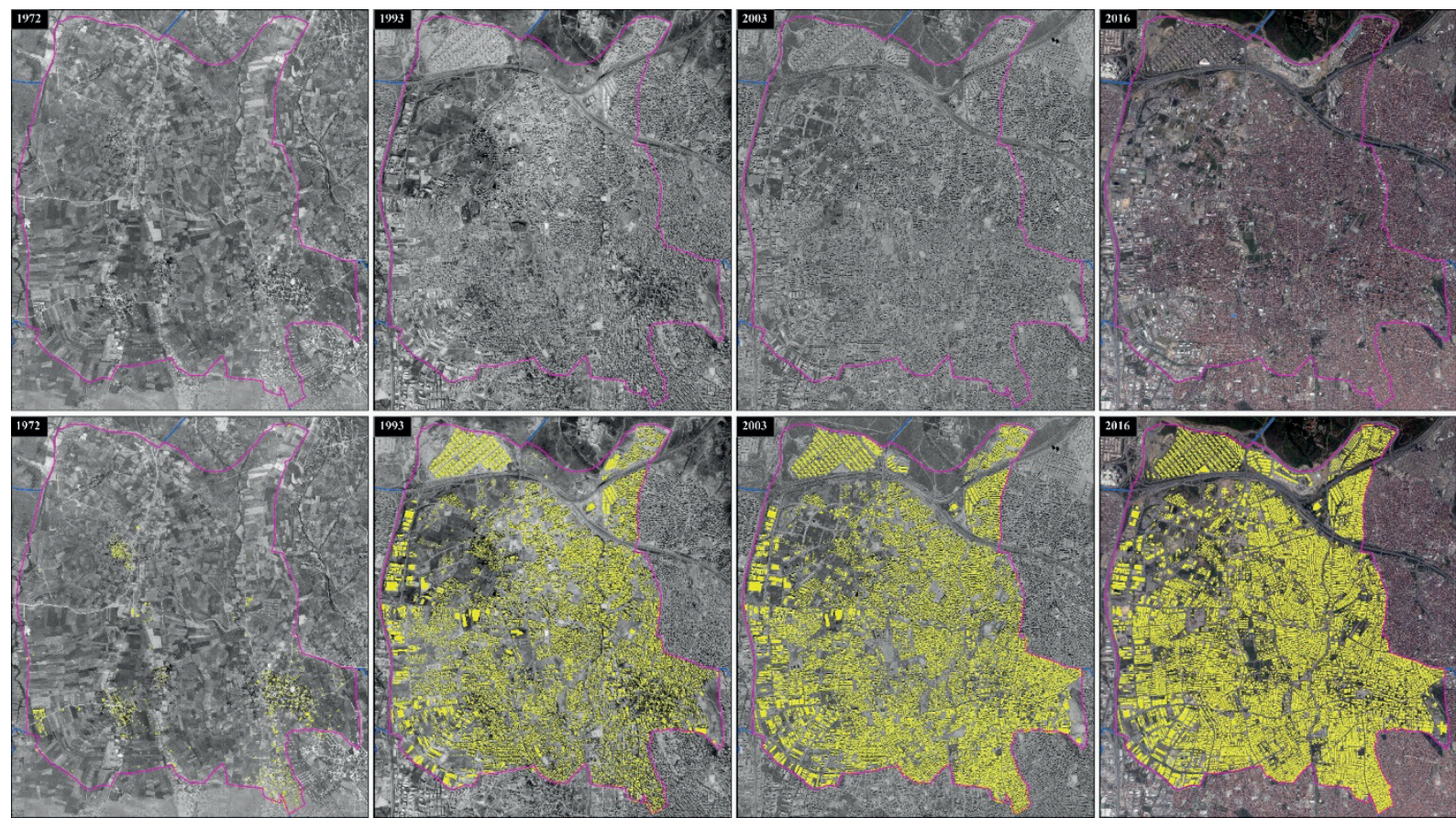

Şekil 1: Bağcılar Şehirsel Alanının Gelişimi.

Figure 1: Development of Bağcılar Urban Area.

eğrisinden çok farklı karakterlere sahip olmasıdır. Bu nispeten ilgili sahanın değişimlere direnci veya daha hızlı uyumu ile ilişkili olsa da, kendine özgü şehirleşme süreçlerine de sahiptir. Örneğin, birbirine yakın mesafede bulunmasına karşın, Erder'in "Bir Kent Kondu: Ümraniye"si ile Işık ve Pınarcioğlu'nun "Enformel Sultanbeyli"sinin şehirleşme dinamikleri arasında önemli farklılıklar bulunmaktadır. Bu husus elbette, İstanbul bütünündeki süreçlerin yerele ait görünümü şekillendirdiği fikrini yok saymıyor ancak yerele ait gömülü yapının İstanbul kentsel bölgesine dair fikirleri şekillendirmede ve yeniden yapılandırmasında etkili olduğunu savunuyor. Dolayısıyla İstanbul kentsel bölgesinde bulunan şehirsel alanların mekânsal formunu anlamlandırmak için her iki ölçekteki özgül yapıyı da dikkate almak gerekiyor ve Bağcılar'ın şehirleşme hikâyesi de yukarıdaki çerçevenin güzel bir örneğini oluşturuyor.

Bu açıdan, İkinci Dünya Savaşı sonrasında İstanbul şehrine katılan diğer alanlar gibi, Bağcılar'ın şehirleşme öyküsü de oldukça kısa... Çünkü Bağcılar'da Bir Şehrin Doğması² sadece yirmi yıllık bir zaman dilimine yayılıyor. Nitekim daha 1970'li yılların başında bile bölge, çoğunlukla nüfus mübadeleleri ile Balkanlardan gelen göçmenlerin yaşadığı kırsal karakterli dört yerleşim biriminden (Mahmutbey, Kirazlı, Güneşli ve Bağcılar) ibaretti. Bu dönemden sonra, başta İstanbul merkezi iş alanı ve çevresindeki sanayi işletmelerinin buraya yerleşmesi, arazi parselasyonunun gerçekleşmesi ve ulaşım imkânlarının gelişmesi ile yörede hızlı bir yapılaşma başlamıştır (Çağdaş, 1990). 1980'li yıllardan itibaren dışa açık ekonomi politikalarının uygulanması ve İstanbul'un küresel ekonomi de yeniden önem kazanması da sürece dinamizm kazandırmıştır (Temurçin, 2013). Pazarın genişlemesine bağlı olarak, özellikle tekstil ve giyim eşyası sanayisindeki ilerlemeler Bağcılar'ın şehirleşmesinde ve günümüzdeki görünümünde önemli bir yer edinmiştir (Temurçin \& Aldırmaz, 2017a; Temurçin \& Aldırmaz, 2017b). 1980 sonrasında kırsaldan gelen küçük miktarlardaki sermaye, yüksek talep nedeniyle konfeksiyon sektörüne aktarılmış ve bu üretim biçimi kısa sürede Bağcılar'ın temel sektörü haline gelmiştir. İfade edilen gelişmelerin neticesinde de, ilçede bina alanları yirmi yılda yaklaşık yirmi kat artmış ve Bağcılar 1993 yılında ilçe statüsü kazanmıştır. Yapılaşma söz konusu dönemden sonrada aynı hızla devam etmiş, ilçe günümüzde İstanbul'un en yoğun yerleşim birimlerinden biri haline gelmiştir (Şekil 1).

Bağcılar'da şehirleşmeyi tetikleyen tarihsel nedenlerdeki sadelik, mekânın inşasındaki özgül yapıyı genellikle gizlemektedir. Nitekim kentin dokusu incelendiğinde, Bağcılar'ın şehirleşme dinamiklerinin ve mekâna yansıyan izdüşümlerinin bir takım farklılıklar içerdiği görülmektedir.

2 Belediyeye ait tanıtım kitapçı̆̆ında şehrin tarihçesi “Bağcılarda Bir Şehir Doğdu” başlığı altında sunuluyor. Söz konusu metinde kırsal alanın dönüşümü 1970’lerde başlıyor. Şehrin oluşumu ise sadece bir kısa paragraftan oluşuyor. 


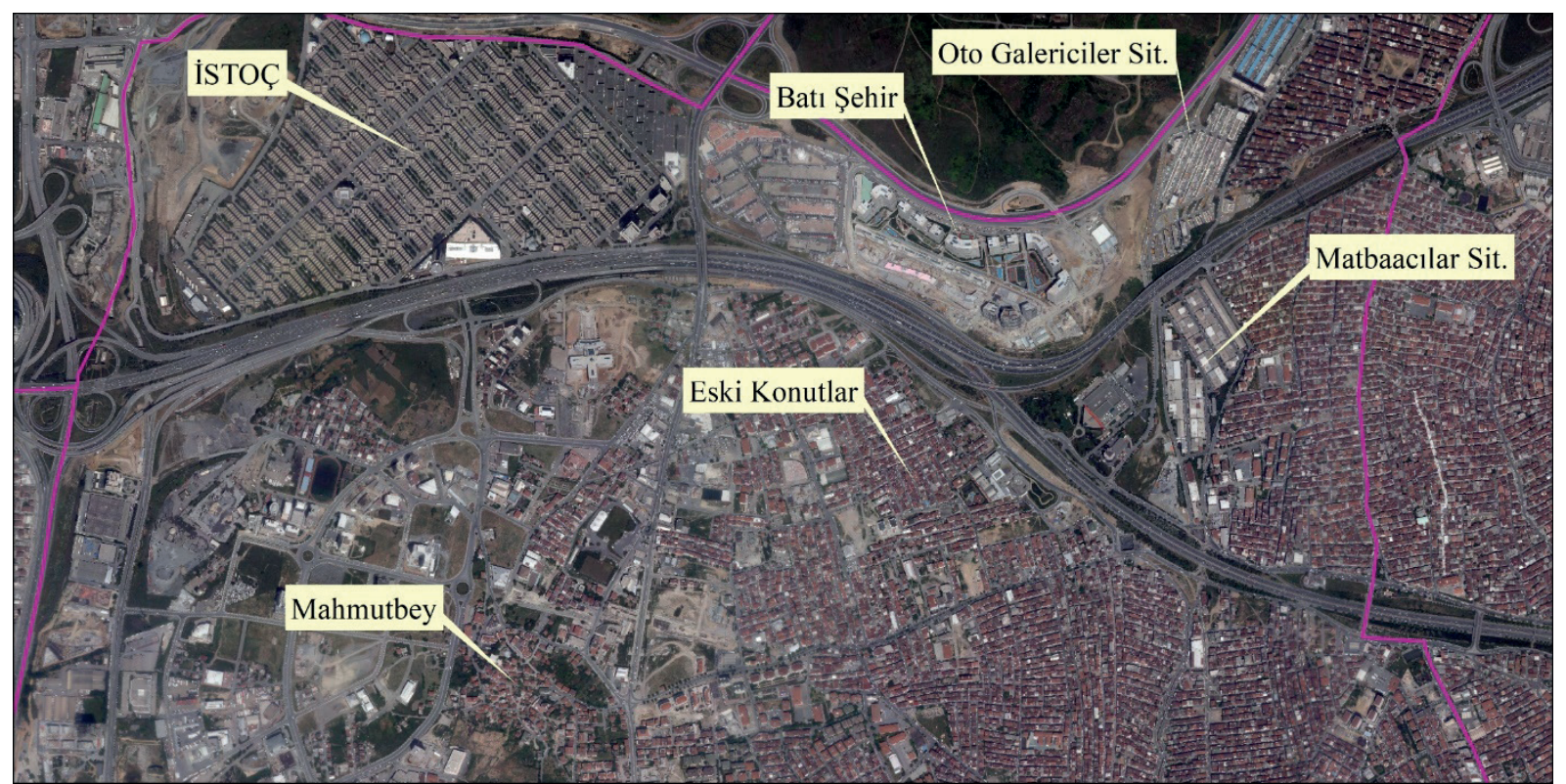

Şekil 2: Bağcılar'da Faklı Konut Sunum Biçimlerinin ve Şehir İçi Arazi Kullanım Biçimlerinin Bir Araya Gelmesi İle Oluşan Sorunlu Mekânsal Doku. Figure 2: Problematic Spatial Texture in Bagcilar with Different Housing Presentation Forms and Urban Land Use Forms.

Bunlardan ilki, İstanbul'un yayılma biçimindeki değişimin bir sonucu olarak, yağ lekesi büyümenin bu dönemde önemini kaybederek yer yer kentsel saçaklanmanın Bağcılar'ın şehirleşme sürecinde -kısa süreli de olsa- gözlemlenmesidir. İlçede şehirleşmenin nüvesini oluşturan dört yerleşme de, İstanbul şehirsel alanından kopuk halde konumlanmış ve kısmen de olsa şehirsel alandan ayrı büyümüştür. Hatta o dönemlerde Kıray, Bağcılar'ın bazı semtlerini İstanbul'un banliyösü olarak değerlendirmiştir (Kıray, 1984). Nitekim 1970'li yıllarında başında, Bağcılar'daki yerleşmeler ile İstanbul şehirsel alanı arasındaki uzaklığın ortalama üç ile altı kilometre arasında olduğu görülmektedir. Ancak 1990'lı yıllardan itibaren, yerleşmeler hem birbirleri ile hem de İstanbul şehirsel alanı ile birleşmişlerdir. Dolayısıyla hem saçaklanma olgusu hem de banliyö statüsü Bağcılar şehirsel alanı için geçici ve kısa süreli bir varsayımdan ibaret kalmıştır. 1970-1993 yılları arasında boşluklar bırakarak günümüz sınırları dâhiline yayılan apartmanlar, 1990'lı y1llardan sonra artık arazinin azalmas nedeniyle boşlukların doldurulması şeklinde bir gelişim çizgisi izlenmiştir. Bu nedenle banliyölerdeki boşluklar bir yana, birçok mahallede yeşil alana rastlamak bile güçtür. Mevcut birkaç ağaçlık alan ise sadece eski köy merkezleri ile sınırlı kalmıştır. İlginç bir şekilde buralardaki yapılar zaman içerisinde yenilense dahi yeşil alan tamamen ortadan kaldırılmamıştır. Diğer mahallelerin çoğunda ise doğal yeşil alan miktarı mahalle yüz ölçümünün \%1'i bile değildir. Birçok mahalle için arazi örtüsü sadece bina ve yollardan ibarettir. Hatta yolların şekli de bu karmaşadan nasibini almıştır. Yaklaşık $22 \mathrm{~km}^{2}$ alanına rağmen ilçede cadde ve sokakların sayısı, 2500'ün üzerindedir. Söz konusu yolların \% 80'i yüz metreden daha kısadır. Sabit bir yönde ilerleyen en uzun yol ise $1 \mathrm{~km}$ 'den daha kısa uzunluğa sahiptir. Çünkü yol ağı ya parseller veya binalar arasına sıkışmış ya da yerleşime uygun olmayan alanlara göre şekillenmiştir. Örneğin şehirsel alanı kuzey güney doğrultusunda kat eden iki önemli ana yol ağı (Yeşilköy Mahmutbey Ekspres Yolu ve Mehmet Akif Bulvarı) iki akarsu deresi üzerine kurulmuştur (Şekil 1).

İkinci farkl11ık ise, konut sunum biçimlerindeki değişimdir. $\mathrm{Bu}$ döneme kadar İstanbul peyzajının temel karakteristiği olan gecekondulaşma, Bağcılar'da önemini yitirmeye başlamıştır. Eski köy merkezindeki binalar hariç tutulursa (özellikle Mahmutbey) mekânsal dokuya daha çok apartmanlar hâkimdir. Bunlar parsellenmiş özel veya hisseli arsalar üzerine kurulsa da, büyük çoğunluğunun planlı ve yasal yapılar olduğunu söylemek güçtür (Çağdaş, 1990; Tekeli, 2013). Yine ilçedeki apartmanların önemli bir kesimi konum, yön ve biçim itibariyle diğerleri ile asimetrik bir şekilde inşa edilmiştir. Ancak asıl uyumsuzluk söz konusu binalar ile 2000 sonrasında inşa edilen lüks konut projeleri (Batı Şehir gibi) arasında gözlemlenmektedir. Bir yanda İstanbul'un uygun konutları diğer yanda ise en prestijli yapıları yan yana durmaktadır. Çelişki, her iki konut sunum biçiminin; zonlama düşüncesinin ürünü olan İSTOÇ ve Matbaacılar Sitesi gibi yapılarla veya şehrin batı-güneybatı kesiminde yer alan büyük sanayi tesisleri ile bir araya geldiğinde daha da artmaktadır. Kısaca günümüzde Bağcılar'da; üretimle tüketim, gelişmişlikle geri kalmışlık, lüksle sefalet, istenilenle istenmeyen küçük bir bölgede sıkışmış durumdadır (Şekil 2). 
Mekânsal dokuda gözlemlenen üçüncü özgül süreç ise, Bağcılar'ın 2000'li yılların başından itibaren şehirsel büyümenin yanı sıra bir yeniden yapılanma/dönüşüm süreci içerisine girdiğidir. Son dönemlerde İstanbul'un mekânsal dokusuna hâkim olan inşaatlar, Bağcılar'da da yaygın haldedir. Bu olgu iki şekilde işlemektedir. İlki eski binaların yerine yenilerinin inşası halindedir. Genellikle tek tek ve az sayıdaki binadan oluştuğu için etkisi oldukça kısıtlıdır. Daha yaygın görülen şekli ise bir zamanlar Bağcılar'da şehirleşmeyi başlatan büyük sanayi tesislerinin hem planlamaların ve diğer sektörlerin/kullanımların yarattığ spekülasyonunu elde etmeleri nedeniyle yer değiştirmesiyle ortaya çıkmaktadır. Bunlara bir de işletmelerin daha esnek üretim biçimlerini benimseyerek ve küçülerek binaların çeşitli katlarına yerleşmesi eklenebilir. Şehrin muhtelif yerlerindeki, ama özellikle de Yeşilköy Mahmutbey Ekspres Yolu çevresindeki tesisler bir bir yıkılarak yerlerine reklamlarda sık sık yer edinen projeler konuşlanmaktadır (Şekil 3). Ancak bu süreç hem Bağcrlar'ın hem de İstanbul'un sanayi sektörünün yok olduğu anlamına gelmemektedir. Çünkü işletmelerin büyük bir kısmı yine İstanbul kentsel bölgesi içerisinde yer almaktadır. Yine birçok küçük işletme Bağcılar'daki binaların katlarında üretim yapmak amaciyla buraya taşınmaktadır (Bak: Sarp vd., 2018). Hâlihazırda kentte faaliyetini sürdüren 4500'e yakın imalathanenin varlığı da bunun en güzel göstergesidir (Şekil 4). Sektör bu haliyle, toptan ve perakende ticaret sektöründen sonra ilçedeki en büyük ikinci faaliyet koludur. Hatta kapanan firmaların oranı incelendiğinde, ticarethanelerde değer daha yüksektir. Başka bir ifadeyle ve daha genel bir söylemle, söz konusu değişim, sektörler veya kullanımların kent içi mekân paylaşımındaki göreli üstünlüklerinin doğal bir sonucudur. Burada doğal olmayan ise, Bağcılar'da bu kademelenmenin ani, uyumsuz ve keyfi bir kalıpta ilerlemesidir.

Bağcllar'ın kentsel dokusuna dair son analiz, şehirsel alandaki firmaların lokasyonlarının oluşturduğu mekânsal kalıba dayanmaktadır. Bu konumsal düzen, aslında mekânsal dokuya dair yorumun başka bir yönünü içermektedir. Buraya kadar sıralananlar kentin belirli bir yükseklikten görünen kısmı ile ilgilidir. Bundan sonrakiler ise, üretilen temsilin açıklanması ile sınırlıdır. Çünkü kent içerisindeki işletmelerin oluşturduğu kalıp, ne herhangi bir yükseklikten algılanabilecek ne de yatay boyutta kavranabilecek boyuttadır. Ancak kentin mekânsal yapısına dair önemli ipuçlarına sahiptir. Nitekim kentin biçimi ile firmaların dağılış düzeni arasında diyalektik bir ilişki vardır. Biri diğerini üretirken aynı zamanda onun tarafından şekillenir, birindeki başarısızlık yine diğerindeki karmaşayı beraberinde getirir. Bu açıdan da kentte her şeyin bir yerinin olması gerektiğine inanılır. Sadece plancının gözünde değil,
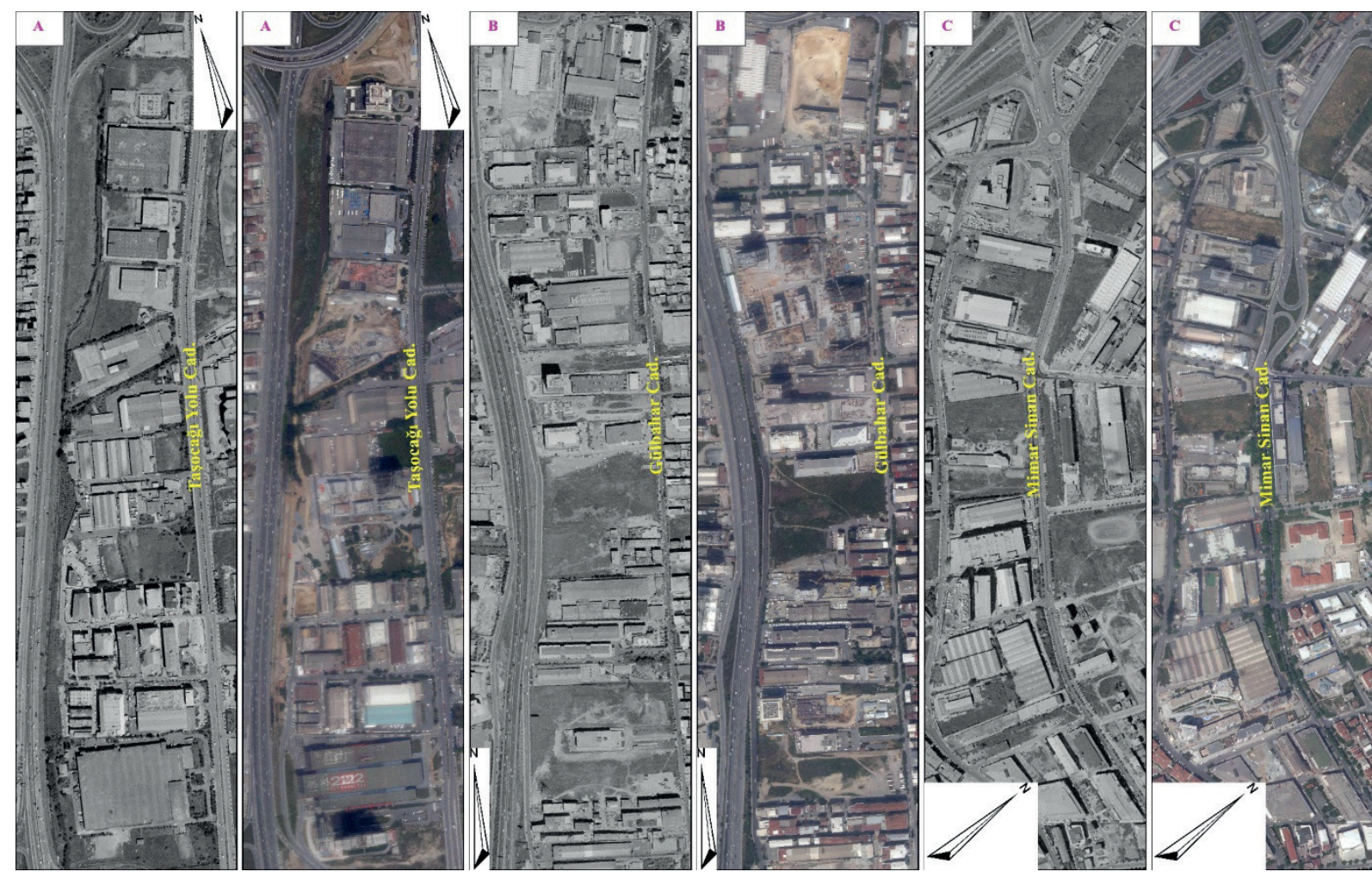

Şekil 3: 2003-2016 Yılları Arasında Dönüşen Alanlardan Bazıları (Siyah Beyaz Görüntüler 2003 Yılına Aittir).

Figure 3: Some of the Areas that Transformed Between 2003 and 2016 (Black and White Images belong to 2003). 
kent teorilerinin çoğunda da böyledir. Belirli yapıdaki veya sektördeki firmaların uygun görülen yerlerde faaliyetlerini sürdürmeleri istenir. Böyle olunca da her bir kullanım için zonlamalara gidilir. Bağcılar'da TEM Otoyolunun kuzeyinde yer alan; Matbaacılar Sitesi, İSTOÇ ve Oto Galericileri Sitesi söz konusu uygulama sonucunda oluşan sahalardır. Özellikle de basım yayım sektöründe faaliyet gösteren firmaların kümelendiği Matbaacılar Sitesi ile toptan satış yapan ticarethaneler ve bunların
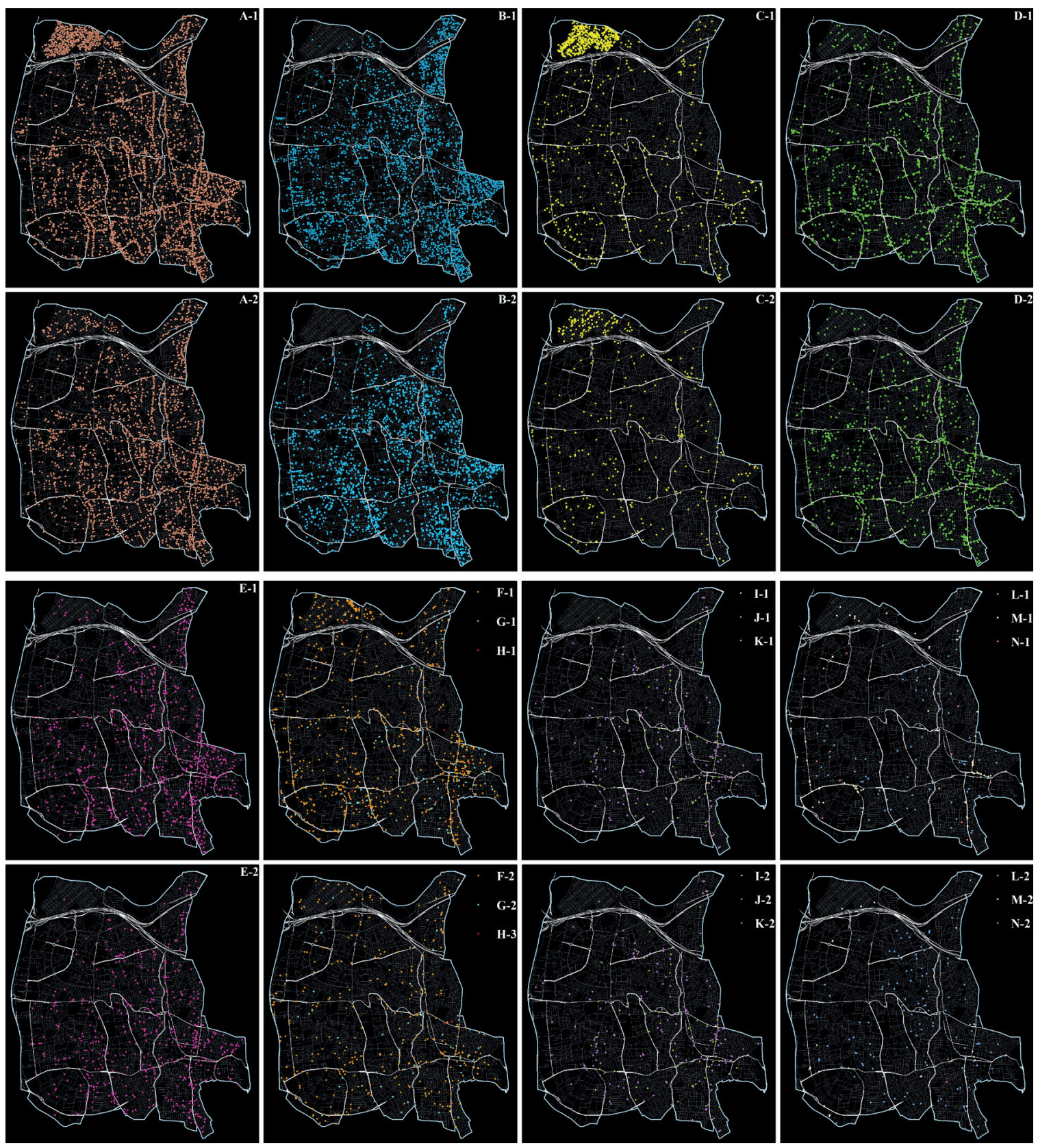

Şekil 4: Bağcılar İlçesinde Kapanan ve Mevcut Firmaların Mekânsal Dağılımı.

Sektörler: A: Toptan ve Perakende Ticaret; Motorlu Kara Taşıtlarının ve Motosikletlerin Onarımı, B: İmalat, C: Ulaştırma ve Depolama, D: Konaklama ve Yiyecek Hizmeti Faaliyetleri, E: Diğer Hizmet Faaliyetleri, F: İdari ve Destek Hizmet Faaliyetleri, G: Gayrimenkul Faaliyetleri, H: İnşaat, I: Eğitim, J: Kültür, Sanat, Eğlence, Dinlence ve Spor, K: Mesleki, Bilimsel ve Teknik Faaliyetler, L: Bilgi ve Iletişim, M: Finans ve Sigorta Faaliyetleri, N: İnsan Sağlığı ve Sosyal Hizmet Faaliyetleri Durumu: 1: Faal, 2: Kapanan

Figure 4: Spatial Distribution of Closed and Active Firms in Bağcılar District.

Sectors: A: Wholesale and Retail Trade; Repair of Motor Vehicles and Motorcycles, B: Manufacturing, C: Transportation and Storage, D: Accommodation and Food Service Activities, E: Other Service Activities, F: Administrative and Support Service Activities, G: Real Estate Activities, H: Construction, I: Education, J: Culture, Arts, Entertainment, Leisure and Sports, K: Professional, Scientific and Technical Activities, L: Information and Communication, M: Finance and Insurance Activities, N: Human Health and Social Work Activities

Status: 1: Active, 2: Closed 
depolarının bulunduğu İSTOÇ ifade edilen sürece dair başarılı örneklerdir. Ancak şehrin geriye kalan \% 95'lik kesimindeki 13 binden fazla firma, herhangi bir zonlamaya tabi kalmaksızın kendi kararlarına göre yer seçimi yapmaktadır. Bu da Bağcılar şehirsel alanında, hemen tüm sektörlerdeki işletmelerin yan yana üst üste faaliyetlerini sürdürmesi anlamına gelmektedir. Dağılış kalıbı incelendiğinde, birbiri ile uyumsuz sektörlerin bile aynı yere oldukları rahatlıkla görünmektedir. Dolayısıyla her bir sektörün oluşturduğu sorunlar aynı mekânda yoğunlaşmaktadır. Firma sayısının ve dağılış düzeninin şekli dikkate alındığında söz konusu problemlerin kentin her yerinde olduğu ortadadır. Daha ilginç olanı ise, kapanan işletmelerin var olanlarla aynı dağılışa sahip olmasıdır. $\mathrm{Bu}$ da ilgili sorun ve düzensizliğin tekrarlanması anlamına gelmektedir (Şekil 4).

\section{SONUÇ}

Son birkaç y1llık nüfus bilgisi İstanbul kentsel bölgesindeki yerleşim birimlerinde bir terk edişin sinyallerini yansitıyor. 2018 verilerine göre ilin nüfus artışı sadece 38 bin gibi şaşırtıcı bir düzeye geriledi ve 39 ilçeden 22 'sinin nüfusu bir önceki yıla göre azaldı. Bağcılar'da söz konusu alanlardan biri... 2016 yılı adrese dayalı nüfus kayıtlarına göre ilçe nüfusu, ilk kez azalmaya başladı ve üç yıl gibi kısa bir sürede de yirmi binden fazla geriledi. Kanımızca hem İstanbul kentsel bölgesinde hem de Bağcılar şehirsel alanında yaşanan bu sürecin temel nedeni mekânsal sorunlara dayanmaktadır. Çünkü her iki ölçekte de kentin dokusu, yaşayanların olağan taleplerini bile karşılamakta yetersiz kalıyor. Özellikle Bağcılar'ın şehirleşme hikâyesi ile benzer tarihsel nedenleri paylaşan yerleşim birimlerinde, söz konusu durum rahatlıkla gözlemlenebiliyor. Kente dair yazınsal birikimdeki değişim de böyle bir çerçeveyi destekliyor ve gittikçe daha fazla disiplin kentin mekânsal yapısı ile ilgileniyor. Nitekim artık kentin mekânsal biçimi, Harvey'in ifadesiyle insan davranışlarının temel belirleyicisi olarak görülüyor (Harvey, 2016). Fakat ifade edilen olgu her kentsel alanda farklı şekillerde işliyor. Bu nedenle de kentin dokusuna dair özgül süreçler önem kazanıyor. Daha da önemlisi söz konusu yapı doğası gereği her ölçekte farklılaşıyor ve detay arttıkça da gerçek olan daha rahat gözlemleniyor. Dolayısıyla yüksek temsil yeteneğine ve çözünürlüğe sahip veriler mekânsalı yorumlamada kritik rol oynuyor.
$\mathrm{Bu}$ çalışmanın mekânsal dokuya dair bulguları da dört farklı gömülü sürece dayanıyor. Ortak noktaları ise, Bağcılar'ın şehirleşme hikâyesine dair anahtar kelimenin "düzensizlik" olduğunu gösteriyor. Nitekim birkaç küçük alan dışında, zonlamanın veya planlamanın getirdiği sınırlandırılmış düzen Bağcllar'da neredeyse hiç yoktur. Bu durum, kentsel mekânda insan algısının üzerinde bir çeşitliliğe neden olmuştur. Öyle ki Jacobs $^{3}$ 'un kentte arzuladığ Bağcllar'da hemen her zaman bir kural haline gelmiştir. Ancak bu çeşitlilik yine onun ifadesiyle kendi kendini yok etmektedir. Çünkü onu var eden düzensizlik, kentin coğrafi anatomisinde patolojik ${ }^{4}$ sorunlara neden olmaktadır. Halen devam eden lokal dönüşümler ise, var olan problemleri yoğunlaştırma eğilimindedir ve durum gittikçe de kronik bir hal almaktadır. Çözüm ise kentin bir bütün halinde dönüştürülmesine dayandırılmaktadır. Belediye Başkanı şehirsel alandaki binaların \%70'inin acilen dönüşmesi gerektiğini vurgulamakta... Ona göre böyle bir değişim gerçekleşirse Bağcılar'ın cefasını çekenler artık sefasını sürecekler. Ancak sağlıklı bir dönüşüm için parsellerin birleştirilmesi de şart ${ }^{6} \ldots$ Bu da her nasıl olursa olsun, yoğun yapılaşma nedeniyle, kentin dikey büyümesi anlamına gelmektedir. Daha da önemlisi şehirsel alanın \%70'inin yeniden yaratılmasının pratikte ne kadar mümkün olacăğ ... Şimdilik beklemek gerek ama mekânsal dokusu tedavi edilinceye kadar Bağcılar'ın geleceği belirsiz...

Teşekkürler: $\mathrm{Bu}$ çalışma Harita Genel Müdürlüğü ile Süleyman Demirel Üniversitesi arasında imzalanan protokol kapsamında yürütülen "Çok Zamanlı Hava Fotoğrafları ve Ortofotolardan Otomatik Olarak Belirlenecek Sanayi Alanlarının Şehir Dokusu Üzerine Mekânsal ve Zamansal Etkisinin İncelenmesi: İstanbul İli Bağcılar İlçesi Örneği” isimli proje kapsamında yapılmıştır. Yazarlar, projenin verilerini sağlayan Harita Genel Müdürlüğüne ve 4972-GÜP-17 numaralı proje ile finansal destek sunan Süleyman Demirel Üniversitesi BAP Birimine teşekkür eder.

Finansal Destek: Bu çalışma Harita Genel Müdürlüğü ile Süleyman Demirel Üniversitesi Arasında İmzalanan Protokol Kapsamında Yürütülen "Çok Zamanlı Hava Fotoğrafları ve Ortofotolardan Otomatik Olarak Belirlenecek Sanayi Alanlarının Şehir Dokusu Üzerine Mekânsal ve Zamansal Etkisinin İncelenmesi: İstanbul İli Bağcılar İlçesi Örneği”" İsimli Proje Kapsamında, Süleyman Demirel Üniversitesi BAP Birimi Tarafindan (4972-GÜP-17 Numaralı Proje ile) Desteklenmiştir.

3 İlgili Çalışma İçin Bakınız: (Jacops, 2017)

4 İtalik kısım Tümertekin'e aittir. İlgili Çalışma İçin Bakınız: (Tümertekin, 1997b)

5 İlgili Haber İçin Bakınız: https://www.aksam.com.tr/guncel/bagcilarin-yuzde-70ini-c2donusturmek-zorundayiz-c2/haber-275631 (Erişim: 02.09.2019)

6 İlgili Yazı İçin Bakınız: http://kentseldonusum.bagcilar.bel.tr/guncel/haberler/Medeniyetimize-uygun-bir-donusum-arzuluyoruz/7/53/0 (Erişim: 02.09.2019) 


\section{KAYNAKLAR}

Akova, S. B. (2012). Ergene Havzasında Şehirler ve Şehirleşme. Sosyoloji Dergisi, Cilt: 3, Sayı: 9, s. 29-51.

Arlı, A. (2010). Murat Güvenç ile İstanbul'un Son Yüzyılı Üzerine. Türkiye Araştırmaları Literatür Dergisi, Cilt 8, Sayı 16, s. 401-433.

Avcu, S., \& Buldur, A. D. (2018). Sultangazi İlçesi'nin (İstanbul) Şehirleşme Süreci. Turkish Studies, Vol. 13, No. 3, pp. 81-126.

Ayhan, F. (2019). Esenyurt İlçesinde Nüfusun Gelişimi ve Bu Gelişimde Rol Oynayan Etmenler. Journal of Urban Academy, Cilt: 12 Sayı: 1, s. 67-81. Castells, M. (1983). The City and Grassroots . London: Edward Arnold. Castells, M. (2017). Kent, Sınıf, İktidar (Çev. Asuman Türkün). Ankara: Phoenix Yayınevi.

Çağdaş, A. H. (1990). Mahmutbey'de Sanayi Gecekondu İlişkisi. İstanbul: İstanbul Üniversitesi Sosyal Bİlimler Enstitüsü Beşeri ve İktisadi Coğrafya A.B.D. Yayınlanmamış Yüksek Lİsans Tezi.

Davis, M. (1990). City of Quartz. New York: Vintage Books.

Davis, M. (2016). Gecekondu Gezegeni. İstanbul: Metis Yayınları.

de Certeau, M. (1988). The Practice of Everyday Life. Los Angeles: University of California Press.

Erder, S. (2013). Istanbul'a Bir Kent Kondu: Ümraniye. İstanbul: İletişim.

Fujita, M. (1989). Urban economic theory. New York: Cambridge University Press.

Glaeser, E. L. (2011). Triumph of the city : how our greatest invention makes us richer, smarter, greener, healthier, and happier. London: The Penguin Press.

Goodchild, M. F. (1992). Geographical Infirmation Science. International Journal of Geographical Information Systems, Vol. 6, No. 1, pp. 31-45.

Gould, P. (1981). Letting The Data Speak for Themselves. Annals of the Association of American Geographers, Vol. 71, No. 2, pp. 166-176.

Güvenç, M. (1993). Metropol Değil Azman Sanayi Kenti. İstanbul, Say1: 5, s. 75-81.

Güvenç, M. (2009). Sunuş. Eski İstanbullular, Yeni İstanbullular (s. s. 7-10). içinde İstanbul: Osmanlı Bankası Arşiv ve Araştırma Merkezi Yayın1.

Güvenç, M. (2018). Kentsel Morfoloji Alanı Kurulurken. II. Kentsel Morfoloji Sempozyumu (s. s.73-79.). İstanbul: Türkiye Kentsel Morfoloji Araştırma Ağı.

Harvey, D. (1996). Justice, Nature and Geography of Difference. Cambridge: Blackwell.

Harvey, D. (2009). Kapitalist Kent. New Left Review, pp. 181-202.

Harvey, D. (2015). Kent Deneyimi Çev. Esin Soğancılar. İstanbul: Sel Yayınları.

Harvey, D. (2016). Sosyal Adalet ve Şehir. İstanbul: Metis Yayınları.

He, Y., \& Weng, Q. (2018). Introduction. Y. He, \& Q. Weng içinde, High Spatial Resolution Remote Sensing (s. pp. ix-xvii). Boca Raton: CRC Press.

Işık, O., \& Pınarcığlu, M. M. (2015). Nöbetleşe Yoksulluk: Gecekondulaşma ve Kent Yoksulları: Sultanbeyli Örneği. İstanbul: İletişim.
Jacops, J. (2017). Büyük Amerikan Şehirlerinin Ölümü ve Yaşamı. İstanbul: Metis Yayınları.

Kıray, M. (1984). İstanbul: Metropoliten Kent. Mimarlık, Y11: 22 Say1: 1, s. 28-33.

Knox, P., \& Pinch, S. (2010). Urban Social Geography. Essex: Pearson Education Limited.

Kolukırık, S. (2012). Göçler ve Kentler: Dilovası Örneğinde Sanayileşme ve Kentleşmenin Sosyolojik Görünümü. Zeitschrift für de Welt der Türken, Vol. 4, No. 1, pp. 125-147.

Kuban, D. (1998). İstanbul Yazıları. İstanbul: Yap1 Endüstri Merkezi Yazıları.

Lefebre, H. (2011). Kentsel Devrim. İstanbul: Sel Yayıncılık.

Maktav, D., Sunar, F., Taberner, M., \& Akgün, H. (2000). Monitoring urban expansion in the Büyükçekmece District of İstanbul Using Satellite Data. International Archives of Photogrammetry and Remote Sensing, Vol. XXXIII, Part B7, pp. 1484-1492.

Massey, D. (2002). Introduction: Geography matters. D. Massey, \& J. Allen içinde, Geography matters! A reader (s. 1-11). New York: Cambridge University Press.

Massey, D., Allen, J., \& Pile, S. (1999). City Worlds. New York: Routledge. Merrifield, A. (2017). Yeni Kent Sorunu. İstanbul: Tekin Yayınevi.

Miller, H. J., \& Goodchild, M. F. (2015). Data-Driven Geography. GeoJournal, Vol. 80, Issue 4, pp. 449-461.

Pacione, M. (2009). Urban Geography. New York: Routledge.

Park, R. E. (2016). Şehir: Kent Ortamındaki İnsan Davraışlarının Araştırılması Üzerine Öneriler. R. E. Park, \& E. W. Burgess içinde, Şehir: Kent Ortamındaki Insan Davraışlarının Araştırılması Üzerine Öneriler (s. 37-88). İstanbul: Heretik Basın Yayın.

Roweis, S. T., \& Scott , A. J. (1978). The urban land question. K. Cox içinde, Urbanization and conflict in market societies. Chicago: Maaroufa.

Sarp, G., Temurçin, K., \& Aldırmaz, Y. (2018). Evaluation of Industrialization Effects on Urbanization and Heat Island Formation Using Remote Sensing Technologies; A Case of Istanbul Bağcılar District. Süleyman Demirel Üniversitesi Fen Edebiyat Fakültesi Sosyal Bilimler Dergisi, Say1: 44, s. 1-13.

Sassen, S. (2000). Cities in a World Economy. London: Pine Forge Press.

Schmid, C. (2014). Henri Lefebvre, Kent Hakk1 ve Yeni Metropol Anaakımı. N. Brennner, P. Marcuse, \& M. Mayer içinde, Kâr İçin Değil Halk İçin Eleştirel Kent Teorisi ve Kent Hakkı (s. 72-99). İstanbul: Sel Yayınları.

Scott, A. J. (1980). The urban land nexus and the state. Pion: London.

Scott, A. J. (2017). The Constitution of the City. Cham: Palgrave Macmillan.

Scott, A. J., \& Storper, M. (2014). The Nature of Cities: The Scope and Limits of Urban Theory. International Journal of Urban and Regional Research, Vol. 39, Issue 1, pp. 1-15.

Smith, N. (2015). Mütenalaştırma, Sınır ve Kentsel Mekânın Yeniden Yapılandırılması. N. Smith, \& P. Williams içinde, Kentin Mütenalaştırılması (s. 29-55). Yordam Kitap: İstanbul. 
Soja, E. W. (1980). The Socio-Spatial Dialectic. Annals of the Association of American Geographers, Vol. 70, No. 2, pp. 207-225.

Soja, E. W. (2000). Postmetropolis. Oxford: Blackwell Publishers Inc.

Storper, M. (2013). Keys to the City. Princeton: Princeton University Press.

Storper, M. (2015). The Rise and Fall of Urban Economies. California: Stanford University Press.

Sun, W., Xu, G., Gong, P., \& Liang, S. (2006). Fractal Analysis of Remotely Sensed Images: A Review of Methods and Applications. International Journal of Remote Sensing, Vol. 27, No. 22, pp. 49634990.

Swyngedouw, E. (2004). Social Power and the Urbanization of Water. New York: Oxford University Press.

Tekeli, İ. (2009). Modernleşme Sürecinde İstanbul'un Nüfus Dinamikleri Nasıl Dğerlendirilmeli. Eski İstanbullular Yeni İstanbullular, (s. s. 11-34). içinde İstanbul: Osmanlı Bankası Arşiv ve Araştırma Merkezi Yayını.

Tekeli, i. (2013). İstanbul'un Planlanmasının ve Gelişmesinin Öyküsü. İstanbul: Tarih Vakfi Yurt Yayınları.

Tekeli, İ. (2019). Ülkesel/Milli Fiziki Plan Üzerine Dördüncü Kez Konuşurken. Journal of Cirt and Regional Planning, Vol. 1, No. 1, pp. 1-14.

Temurçin, K. (2013). The development and structure of industry in the disrict of Bağcılar(İstanbul). Bulletin of Geography-Socio Economic Series, No. 20, s. 95-111.
Temurçin, K., \& Aldırmaz, Y. (2017a). İstanbul İlinde Tekstil, Dokuma ve Giyim Sanayi: Yapısı, Özellikleri ve Dağılışı. F. Arslan içinde, Türkiye Coğrafyası Araştırmaları (s. s. 271-294). Ankara: Pegen Akademi Yayıncılık.

Temurçin, K., \& Aldırmaz, Y. (2017b). İstanbul İlinde Sanayi: Tarihsel Gelişim, Yapısal Değişim, Mekânsal Dönüşüm. K. Temurçin, \& M. A. Dulupçu içinde, Türkiye'de Mekânsal ve Bölgesel Dönüşümler (s. s. 1-14). Isparta: Süleyman Demirel Üniversitesi Yayınları.

Theodore, N., Peck, J., \& Brenner, N. (2011). Neoliberal Urbanism: Cities and the Rule of Markets. G. Bridge, \& S. Watson içinde, The New Blackwell Companion to the City (s. 15-25). Oxford: Blackwell Publishing.

Tümertekin, E. (1997a). İstanbul İnsan ve Mekân. İstanbul: Tarih Vakfi Yurt Yayınlar1.

Tümertekin, E. (1997b). İstanbul Şehrinin Coğrafi Anatomisi. Kent Gündemi, Say1: 1, s. 41-47.

Welch, R. (1982). Spatial ResolutionRequirements for Urban Studies. International Journal of Remote Sensing, Vol. 3, No. 2, pp. 139146.

Weng, Q. (2014). Characterizing, Measuring, Analyzing and Modelling Scale in Remote Sensing: An Overview. New Jersey: John Wiley \& Sons, Inc.

Weng, Q., Quattrochi, D., \& Gamba, P. E. (2018). Urban Remote Sensing. Boca Raton: CRC Press. 
